\title{
Editorial (ERPP Issue 8.3)
}

\author{
Oon-Seng Tan
}

Received: 6 September 2009 / Accepted: 8 September 2009 / Published online: 19 September 2009

(C) Springer Science+Business Media B.V. 2009

\begin{abstract}
Welcome to the third issue of ERPP for the year 2009. In this issue, we will explore a wide-range of educational policy and practice topics pertinent to New Zealand, Hong Kong, Malaysia, Australia, Laos and the Philippines. The issues are varied, ranging from educational reform and school improvement to children's representations and explanations of arithmetic word problems. Analyses have been conducted using quantitative and qualitative methodologies with implications considered for policy and practice, as well as further research.
\end{abstract}

Stringer observes that capacity building is often mentioned synonymously with school improvement in the literature but lacks consideration of political, social and economic trends. In order to address this lacuna, the author examines the notion of capacity building for school improvement in the context of one New Zealand primary school. The study is positioned within an interpretivist paradigm, and utilizes a case study and grounded theory approach to explore four aspects: (i) processes that enhance improvement; (ii) internal and external influences on capacity building; (iii) wider societal factors that influence the development of capacity; and (iv) links between capacity building and improvement. The article suggests that capacity building for school improvement is time and context dependent. In addition, it argues that the confluence of contributing factors is necessary for the enablement of the tensions and needs of specific contexts to be managed in ways that ensure equilibrium between people, school and system. This builds capacity while moving in the direction of improvement.

$\mathrm{Ng}$ explores how young people are transformed into active and participatory citizens in the educational context of Hong Kong. He uses a case study approach with data collected from focus group, and individual interviews with secondary school students and civic education teachers. The study unravels a three-stage political socialization process of secondary school students in Hong Kong, involving the influence of civic education teachers and their personal attributes, the teaching methods employed and the emergence of civic identities and responsibilities through social participation. Another key finding that emerges from the data is that effective transformation requires effective socializing agents. Yet $\mathrm{Ng}$ laments the

O.-S. Tan $(\bowtie)$

National Institute of Education, Nanyang Technological University, Singapore

e-mail: oonseng.tan@nie.edu.sg 
paucity of teachers who are consciously committed to designing and utilizing pedagogies that enable students to construct and reconstruct the notion of active and participatory citizenship. $\mathrm{Ng}$ explores this problem and considers implications in the light of the above chasm.

Chinnappan and Pandian report a study on the differences in the ways students from Malaysia and Australia interpret and solve arithmetic word problems. Students were presented with numeracy problems, and required to explain and justify their solutions. The authors analysed the students' responses using the frameworks of representation, schema and dialogue. Results showed that both groups did not generate significantly different representations nor was there sufficient evidence to suggest that the two groups differed in the types of schemas activated during the course of solving the problems. Australian students, however, tended to develop explanations that were superior in length and variety in comparison to their Malaysian counterparts. The authors discuss possible reasons for these findings and conclude with suggestions for further research.

The article by Hungi and Postlethwaite reports on a portion of a major project that sought to examine the quality of primary education in Laos. In this particular study, the authors examined key pupil- and school-level factors that influenced reading and mathematics achievement among Grade 5 primary school pupils. Results at the provincial level showed that the urban/rural factor contributed to student achievement. At the school level, it was found school resources and average textbook ownership in class were the main predictors for both reading and mathematics achievement. Other school variables that were found to have significant effects on achievement were grade repetition, sex of school head, average extra tuition, tests in mathematics, and average homework in mathematics. At the pupil level, the factors influencing difference among pupils were pupil sex in mathematics, pupil age, speaking Lao at home for reading performance, distance from school, days absent, family attention, socioeconomic status of the family, grade repetition, homework given and textbook ownership. The authors discuss policy implications in the light of these findings.

In the final article of this issue, Nebres argues that educational reform in developing countries such as the Philippines, should begin with work on macro-problems focussing on the social, political and economic environment of the schools, before proceeding to attend to micro-problems which involve the usual concerns of curriculum, teacher-training, and textbooks amongst others. The article recounts how such an approach to education reform was carried out in three-large scale initiatives in the Philippines, all of which produced very promising results.

As in the case of all issues of ERPP, we hope that the articles in this issue will serve to generate further discussion and collaboration among educators and researchers internationally, so that good educational philosophies and practices may be globally shared. We look forward to your valuable contributions to the ERPP. 